\title{
ANÁLISE SOBRE IMPLANTAÇÃO DO SISTEMA DE MOBILIDADE NO GERENCIAMENTO DA ROTINA DE MANUTENÇÃO EM UMA CERVEJARIA
}

Hellen Cristina Gonçalves Sousa1; Lunalva Carvalho Pinheiro de Mâcedo²; Paulo Figueiredo ${ }^{3}$

1,2,3 Centro Universitário SENAI CIMATEC, BA, Brasil, Av. Orlando Gomes, 1845 Piatã, Salvador, 41650-010. E-mail.: hellengoncalves.souza@gmail.com; lunalvarcp@hotmail.com

Resumo: $O$ estudo tem como principal objetivo demonstrar que através da implantação e utilização de um sistema de mobilidade através do aplicativo SIGGA BRIZZO, a possibilidade de reversão de resultados dos indicadores de desempenho de manutenção, aumentando a sua produtividade, otimizando mão-de-obra garantindo uma maior disponibilidade e confiabilidade nos equipamentos do processo produtivo. O método utilizado foi o estudo de caso na Cervejaria Camaçari, com enfoque qualitativo, através de técnicas de coleta de dados, entrevistas semiestruturadas, análise de documentos do sistema de informação e os monitoramentos apresentados nos gráficos de controle da produção, revisões bibliográficas através de livros, artigos e periódicos, a fim de obter-se o embasamento teórico.

Palavras-Chave: Manutenção; Sistema de Mobilidade; Eficiência; Indicadores de desempenho.

\section{ANALYSIS OF DEPLOYMENT OF THE SYSTEM OF MOBILITY IN THE MANAGEMENT OF ROUTINE MAINTENANCE ON A BREWERY}

\begin{abstract}
O$ estudo tem como principal objetivo demonstrar que através da implantação e utilização de um sistema de mobilidade através do aplicativo SIGGA $\mathrm{BRIZZO}$, it has the possibility of reversal of results of performance indicators of maintenance, increasing its productivity, optimizing workforce and thus ensuring a greater availability, Reliability of the equipment of the production process. The method used was a case study in the Camaçari Brewery, with a qualitative approach, through data collection techniques Semi-structured interviews, document analysis of the information system and the monitoring presented in graphs of production control, bibliographical revisions through books, articles and journals, in order to obtain the theoretical foundation.
\end{abstract}

Keywords: Maintenance; System of mobility; Efficiency; Performance indicators. 


\section{INTRODUÇÃO}

Visando o aumento de competitividade no mercado, as empresas buscam meios de tornarem seu sistema produtivo mais eficiente. Um sistema produtivo eficiente utiliza ferramentas e métodos para auxiliar no aumento da produtividade dos equipamentos. A manutenção, se utilizada da maneira correta, torna-se uma eficiente aliada na busca de um sistema de produção ideal (RIBEIRO, 2003) ${ }^{1}$.

A falta de manutenção nos equipamentos pode causar paradas, produção com capacidade abaixo da necessária ou produtos defeituosos. Essas situações resultam em custos e perdas na produção, além de causar redução de credibilidade com o cliente (DEMING, 1993) ${ }^{2}$. Há algum tempo, o baixo cumprimento dos indicadores de manutenção como: Eficiência de Planejamento, Eficiência de Programação, Tempo Médio de Solução de Anomalia (TMSA), Produtividade Mão de Obra (PMO), Tempo Médio de Reparo (MTTR), Tempo Médio Entre Falhas (MTBF), Cumprimento de Preditivas, que são os meios para se alcançarem os resultados, refletem no desempenho da produtividade.

\subsection{Manutenção}

As operações de manutenção existem para proporcionar que os equipamentos continuem a realizar as tarefas das funções para quais foram projetadas. Assim, a manutenção preventiva e a corretiva programada podem desempenhar um papel essencial na melhoria da produtividade. Um bom processo de planejamento e programação dentro da manutenção irá garantir a confiabilidade dos equipamentos, pois, intervenções realizadas no momento correto vão minimizar os efeitos de eventos não programados.

\subsubsection{Manutenção Preventiva}

Refere-se a manutenção realizada de forma a proporcionar o funcionamento do equipamento dentro de um estado específico, de maneira a reduzir ou evitar falhas ou queda no desempenho, obedecendo a um plano previamente elaborado, baseado em intervalos definidos de tempo. A manutenção preventiva pode ser dividida, de acordo com (HOLSBACH \& CALIL, 2005; HOLSBACH, VARANI \& CALIL, 2005) em:

Manutenção preventiva programada ou sistemática: ocorre quando as ações de manutenção são efetuadas de maneira periódica, mediante intervalos préestabelecidos, dias de calendários, ciclos de operações, horas de operações e outros, desprezando as condições dos componentes envolvidos.

Manutenção preventiva condicional: é aquela realizada nos equipamentos quando estão na iminência de apresentar falhas. A detecção desse estado de quase falha é possível através da utilização dos sentidos humanos ou de aparelhos eletrônicos que monitoram algum parâmetro de desempenho dos equipamentos.

Manutenção preventiva preditiva: é efetuada com base em modificação de parâmetro de condição ou desempenho, cujo acompanhamento obedece a uma sistemática. Também pode ser definida como aquela que indica as condições reais de funcionamento das máquinas com base em dados que informam o seu desgaste ou seu processo de degradação. Trata-se de uma importante ferramenta da manutenção, 
pois visa acompanhar o equipamento ou as peças, por meio de monitoramento, por medições e por controle estatístico para "predizer" a ocorrência de uma falha. Os objetivos principais da manutenção preditiva são, de acordo com (MARÇAL, CHIOCHETTA, HATAKEYAMA, 2004)4: otimizar a troca de componentes estendendo o intervalo de manutenção; eliminar desmontagens desnecessárias para inspeções; impedir o aumento de danos; reduzir o trabalho de emergência não-planejado; aumentar o grau de confiança de um equipamento, em linhas gerais, possibilitando predizer quando os componentes de um equipamento estarão próximos do seu limite de vida.

\subsubsection{Manutenção Corretiva}

Manutenção efetuada para a correção de falha ou do desempenho menor do que o esperado, ou seja, é realizada depois que a falha ocorre, gerando a paralisação dos equipamentos. Devido a isso, é bastante dispendioso no ponto de vista econômico. Segundo $\mathrm{HOLSBACH}^{5}$, é fundamental para execução de uma manutenção corretiva uma equipe composta de: Domínio das informações; Documentação técnica; Instrumentos, ferramentas e/ou equipamentos; Conhecimento aliado com experiência; Princípios de funcionamentos; Capacitação.

\subsection{Planejamento e Gestão da Manutenção}

A manutenção não pode ser considerada como uma ação isolada. Ela é uma parcela agregada do sistema desde a concepção do projeto, seja de um equipamento ou de uma instalação, até o momento que se resolve a desativação destes. Para que as operações de manutenção se desenvolvem, são necessárias algumas condições básicas, que de acordo com as características do lugar a ser atendido e com a procura solicitada, possuem maior ou menor influência no modo de atuação. Segundo Heinritz e Farrel $(1994)^{6}$, nos últimos anos, um crescente número de profissionais com treinamento e experiência em áreas específicas de engenharia, tem ingressado nos setores de compras.

\section{METODOLOGIA}

Utilizou-se como método, o estudo de caso na Cervejaria Camaçari, com enfoque qualitativo, para isso foi utilizada técnicas de coleta de dados, entrevistas semi-estruturadas, também foram analisados documentos do sistema de informação e os monitoramentos apresentados nos gráficos de controle da produção, juntamente com a revisão bibliográfica, a partir de livros, artigos e periódicos, a fim de obter-se o embasamento teórico acerca da manutenção. Para Gil (2002, p58)7, "O estudo de caso é definido pelo estudo aprofundado de um ou poucos objetos, de maneira que permite um conhecimento detalhado".

\subsection{Situação Mapeada na Empresa}

Entre planejamento e execução da manutenção existem muitas variáveis que acabam tornando o caminho para solução da anomalia mais longo. Abaixo seguem 


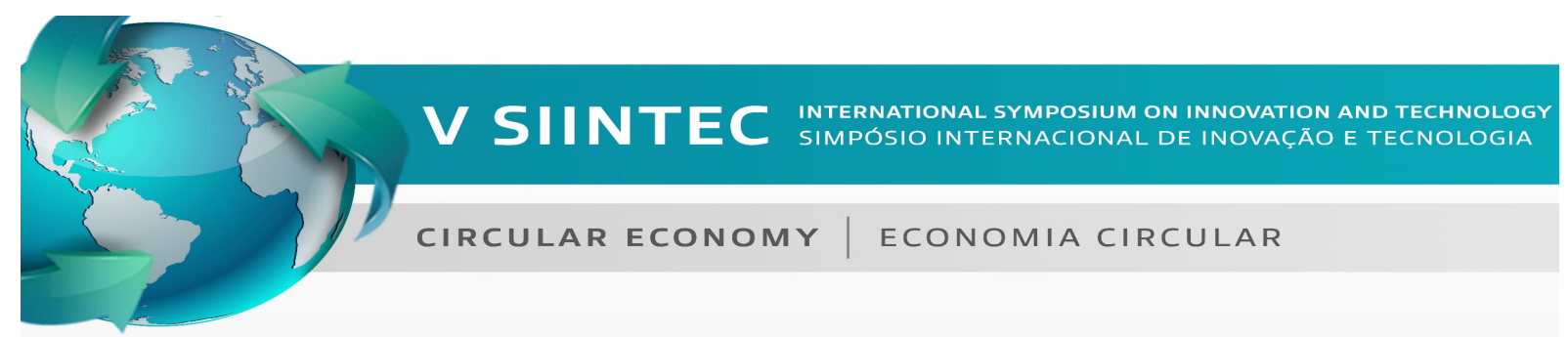

os principais problemas/desafios na gestão da manutenção: Aumento do tempo médio de solução de anomalia: tempo entre relato da anomalia (abertura de nota através do SAP PM), detalhamento da nota, criação da ordem de serviço, programação, impressão de O.S. até resolução final e encerramento da ordem de serviço; Erro de detalhamento de ordens de serviço: ordens de serviço saem para execução sem separação prévia de materiais ou até mesmo sem os materiais necessários para execução; Aumento do tempo médio de reparo (MTTR); Queda na produtividade de mão de obra: técnicos perdem muito tempo com locomoção entre oficinas de manutenção, almoxarifado e linha de produção/áreas. Esse tempo de locomoção está relacionado a requisição de ferramentas e peças; Baixa qualidade nas análises de falha das quebras ou atendimentos emergenciais; Baixa qualidade na execução de manutenção.

\subsection{Melhorias Propostas}

Visando resolver essas principais problemáticas, foi implantando na cervejaria uma nova ferramenta, uma solução tecnológica e inovadora, um sistema móvel de gestão da manutenção. Consiste em um aplicativo, SIGGA BRIZZO, instalado em um smartphone de uso individual e intransferível de cada técnico de manutenção. $O$ aparelho funciona apenas na rede de internet instalada exclusivamente para esse sistema móvel. Para planejar, programar e controlar a manutenção, o setor de Planejamento utiliza um dos mais conceituados softwares para o seu gerenciamento, o sistema SAP-PM, e ainda possui uma nova ferramenta o aplicativo SIGGA BRIZZO, desenvolvido para que os usuários da manutenção possam utilizá-lo durante a execução das atividades em campo, conforme figuras 1, 2 e 3.
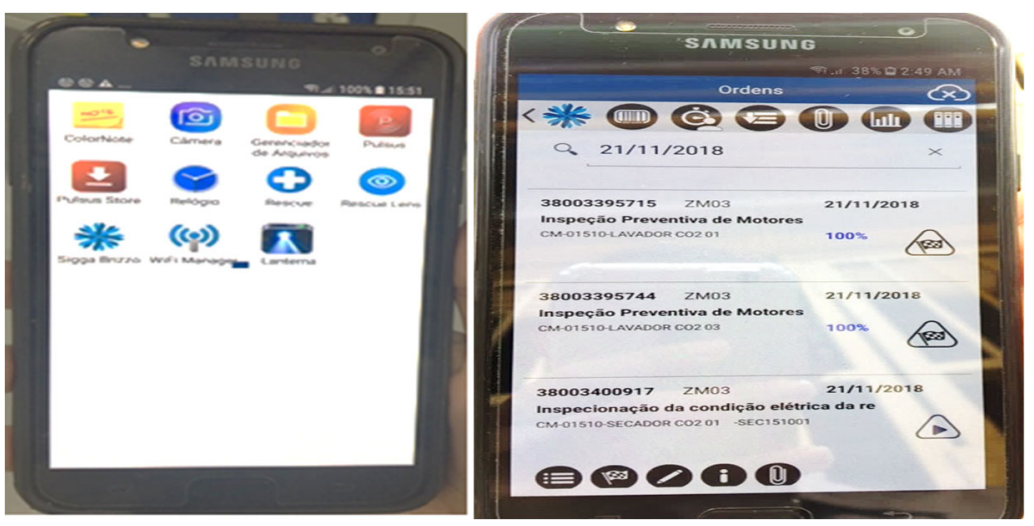

Figura 01: Smartphone com aplicativo SIGGA BRIZZO instalado e em funcionamento

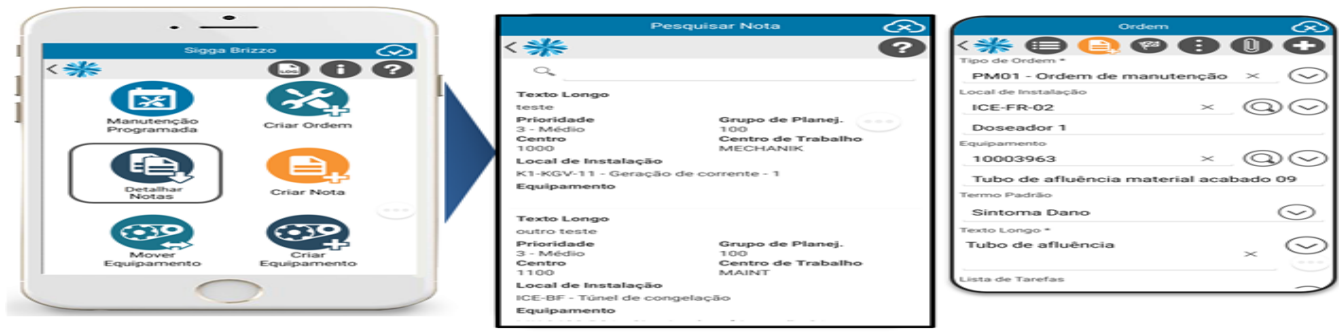

Figura 02: Funcionalidades do aplicativo 


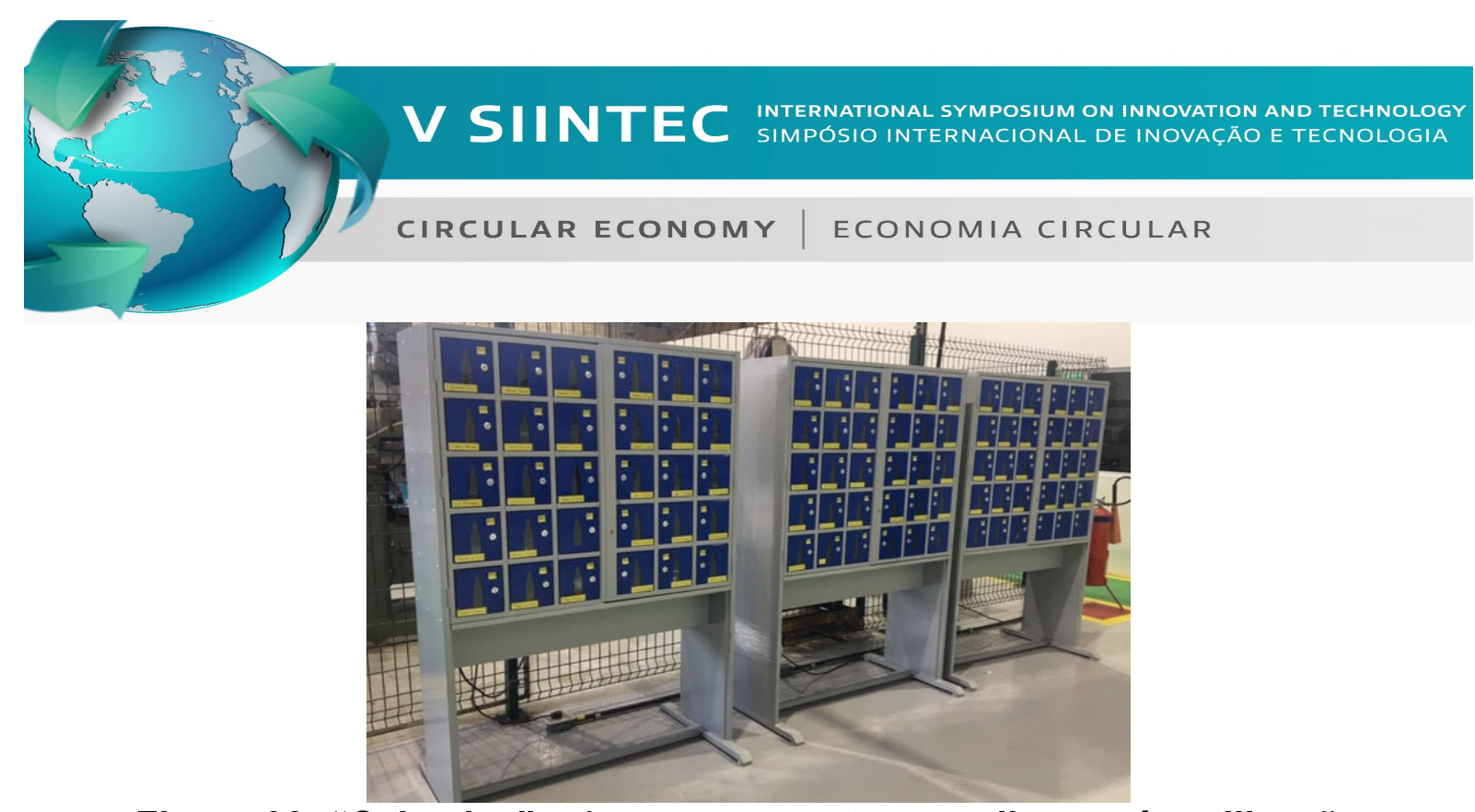

Figura 03: “Celmeias" p /armazenamento aparelhos após utilização

O PCM é responsável por disponibilizar todas as atividades referidas à manutenção no próprio sistema, para que assim os executantes possam realizar suas tarefas diárias. O referido sistema dispõe de um módulo para comunicação com o SAP o qual irá atualizar os trabalhos e consultar novos itens a serem trabalhados e registrados pelos coletores de dados. Os colaboradores da empresa foram treinados por etapas, conforme cronograma de implantação e treinamentos abaixo. Foram também selecionados técnicos com maior desenvoltura e aprendizado para atuarem como multiplicadores do conhecimento na ferramenta, afim de monitorar e minimizar as dificuldades ou falhas do app, conforme figuras 4 .

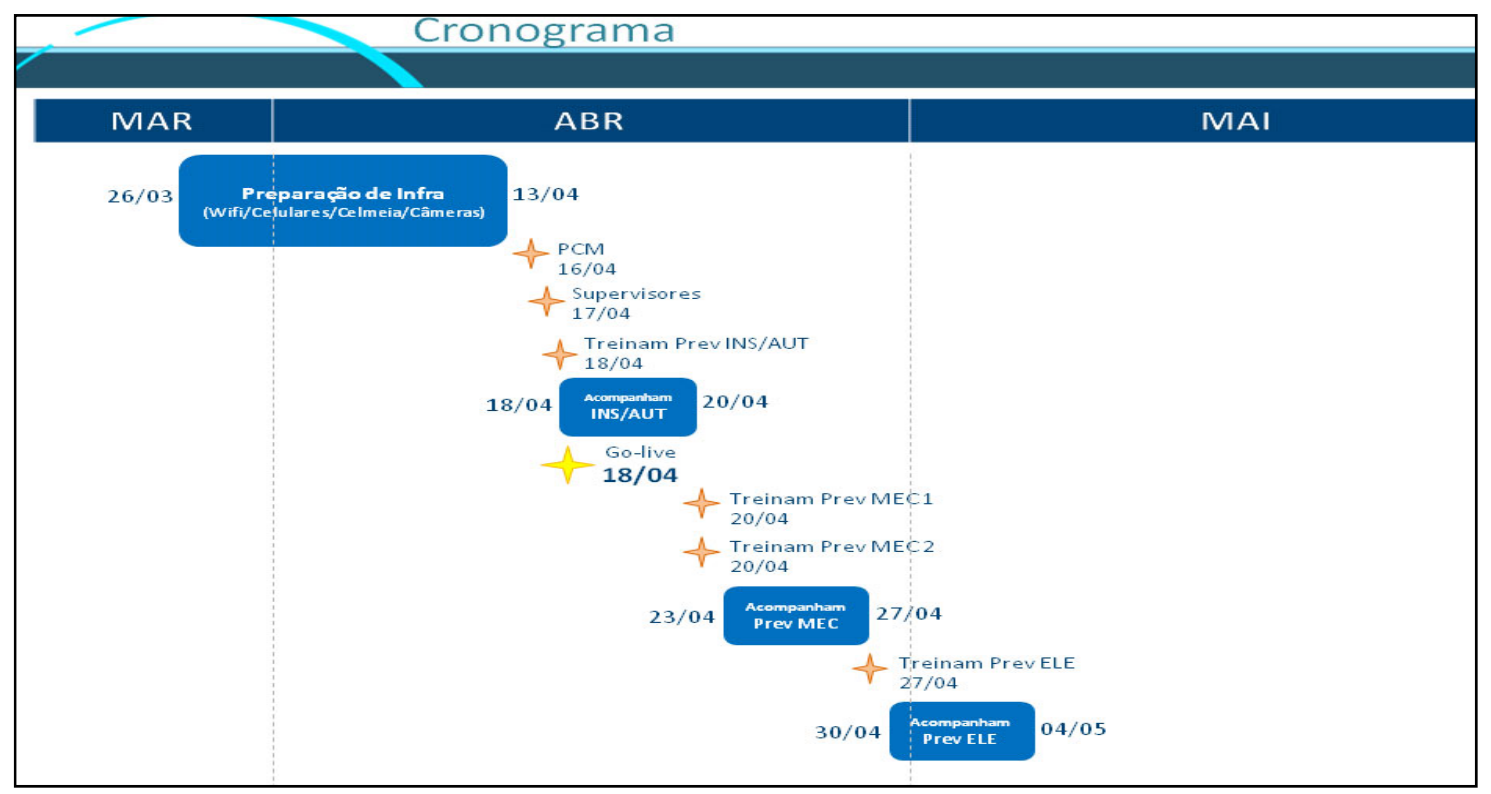

Figura 04: Cronograma de treinamento

\subsubsection{Objetivos da Implantação}

Abaixo foram listados alguns dos objetivos alcançados com a implantação do sistema móvel de Gestão Da Manutenção: Eficácia na mão-de-obra e execução das atividades; Interface com o Sistema ERP (SAP); Geração dos monitoramentos das máquinas e execução das manutenções preventivas e preditivas; Verificação do 


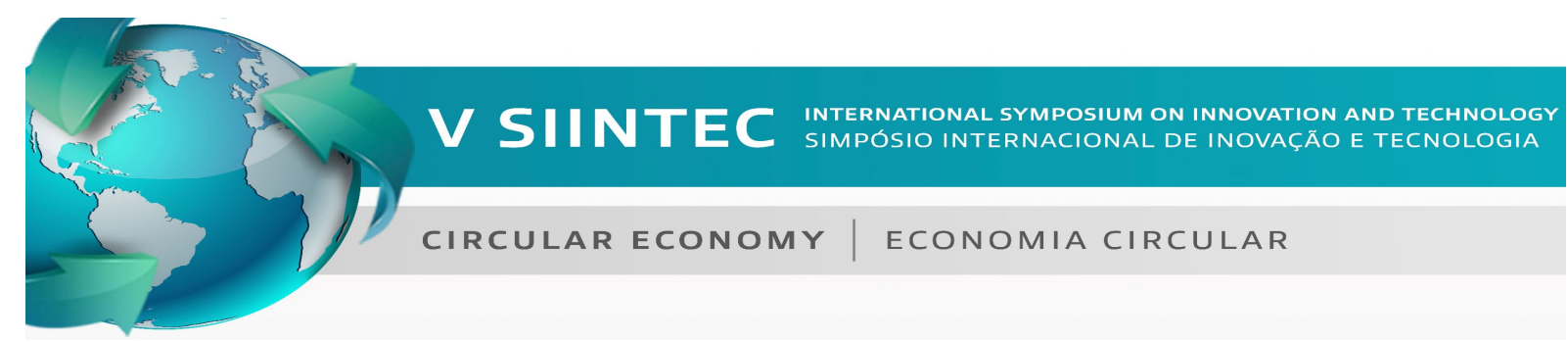

equipamento in loco; Informações disponíveis em tempo real na nuvem através do sistema de monitoramento; Eliminação de retrabalhos; Redução dos tempos de detalhamento das atividades relacionadas à manutenção.

\subsubsection{Benefícios do aplicativo SIGGA BRIZZO}

- Despacho eletrônico de ordens: agiliza o atendimento a chamados de manutenção; Integração com SAP PM: elimina a necessidade de digitadores para entrada de dados; Acesso online e off-line: reduz deslocamentos, otimiza tempo e mão de obra para mais tarefas ao dia; Localização de equipamentos via GPS ou Beacons; Identificação de ativos por QR Codes, RFID, GPS e Beacons (BlueTooth); Apontamento simplificado e automático de tempos de mão de obra (play/stop); Controle de ordens por operação (finalizada, pausada, em execução); Listagem e apropriação de notificações de reparo no aplicativo;

Alguns pontos relacionados ao aprendizado após implantação dos sistema móvel de gestão da manutenção estão listados no quadro 01.

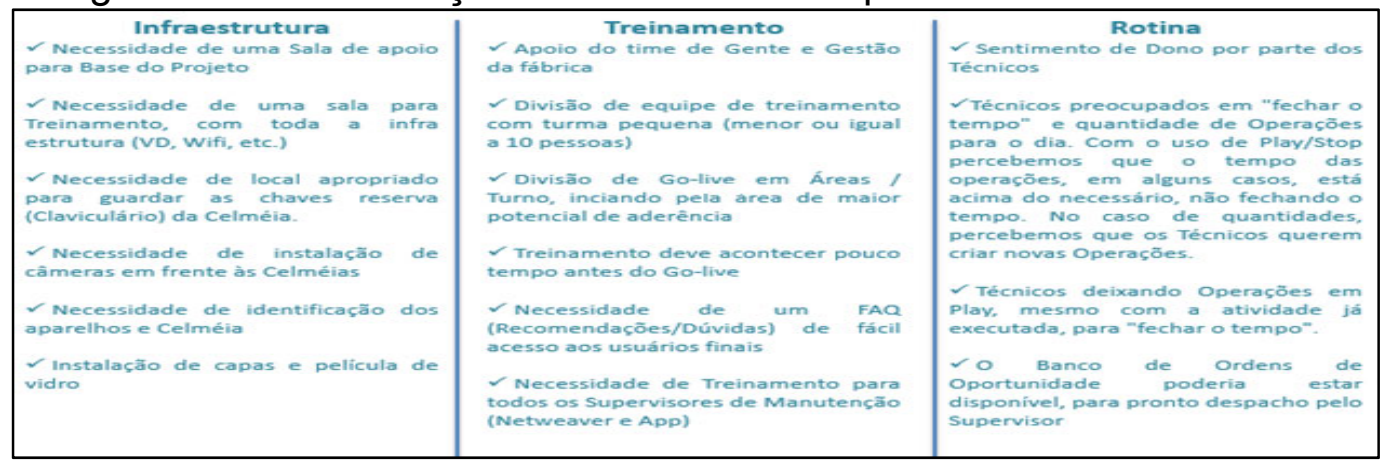

Quadro 01: Lista de aprendizado

\section{RESULTADOS E DISCUSSÃO (ARIAL 12)}

Após implantação do sistema foi registrado um aumento exponencial na execução de ordens de serviço, evolução nos monitoramentos registrados pelos técnicos de manutenção e melhoria também nos registros de atendimento emergencial, o que facilita a análise da falha das máquinas e equipamentos, conforme demonstrado no gráfico 01.

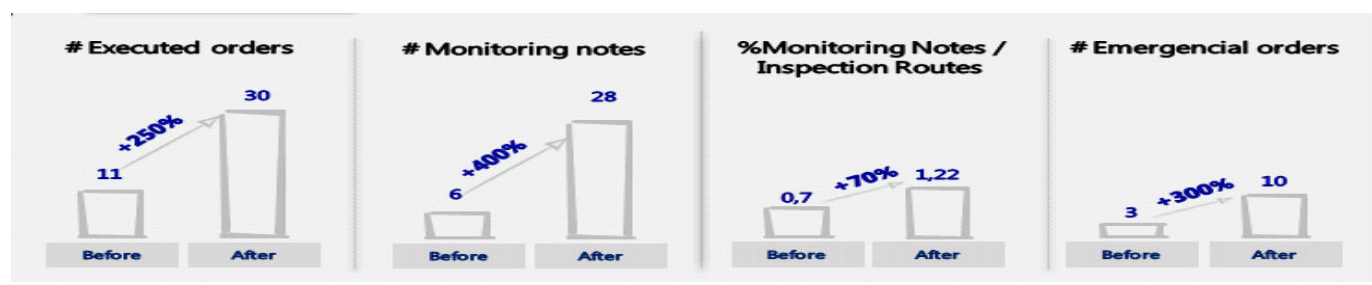

Gráfico 01: Mapeamento de Ordens de Serviços

Com a utilização correta do SIGGA BRIZZO a equipe de planejamento ganhou tempo, pois, não dispensa mais tanto tempo de sua rotina para detalhamento de notas, 
pois, os técnicos de manutenção geram ordens detalhadas descrevendo tempo necessário para execução, materiais, ferramentas, condição de instalação, etc. Ganho também na eficácia do planejamento de manutenção, conforme demonstrado no gráfico 2 com as melhorias ao longo do tempo.

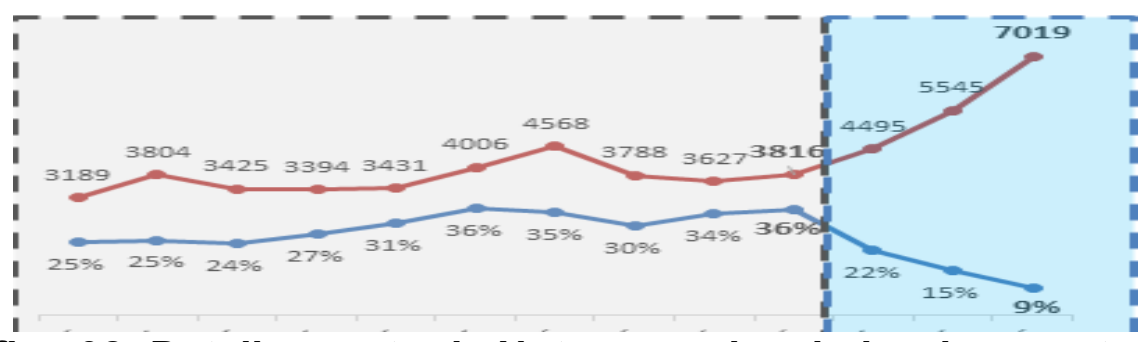

Gráfico 02: Detalhamento de Notas por planejador de manutenção

Foi acompanhado dia a dia a utilização efetiva do aplicativo nas rotinas de manutenção dos técnicos, visando identificar as dificuldades ou falhas no processo, conforme gráfico 03 .

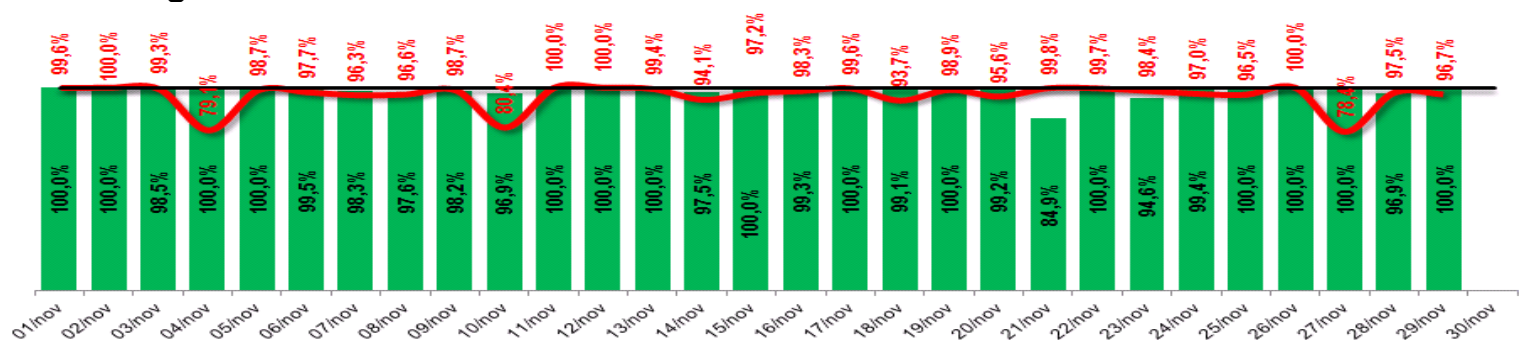

\section{Gráfico 03: Evolução dia a dia da utilização do app Sigga Brizzo}

Com uma boa aderência à nova ferramenta foi observado uma evolução nos registros de anomalia ou monitoramento aberto por inspeção preventiva realizada por técnico de manutenção, conforme gráfico 04.

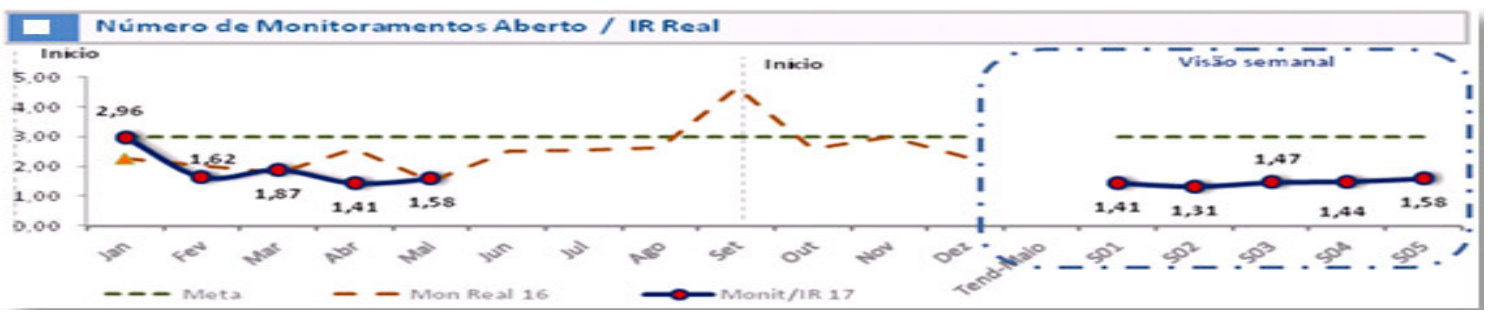

Gráfico 04: Monitoramentos aberto $X$ inspeção de rota

Notou-se uma redução no backlog de ordens de serviço e logo, no tempo médio de solução da anomalia (gráficos 05 e 06), reduzindo assim as quebras e atendimentos emergenciais.

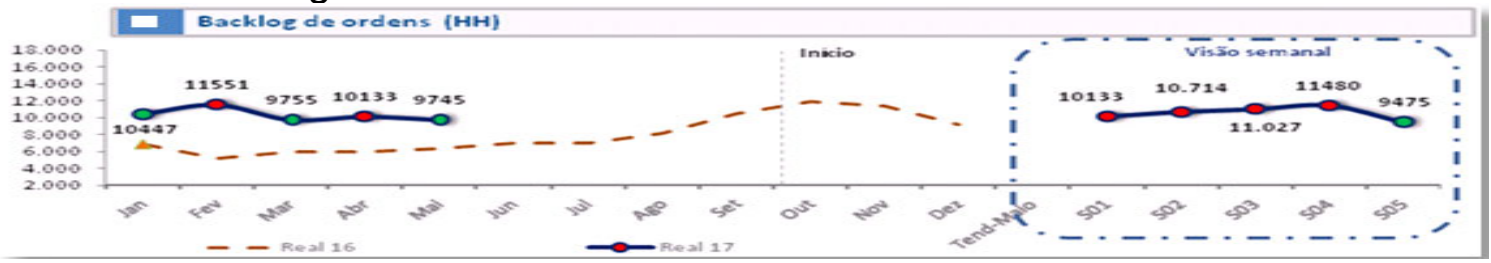

Gráfico 05: Redução de backlog de ordens por horas 


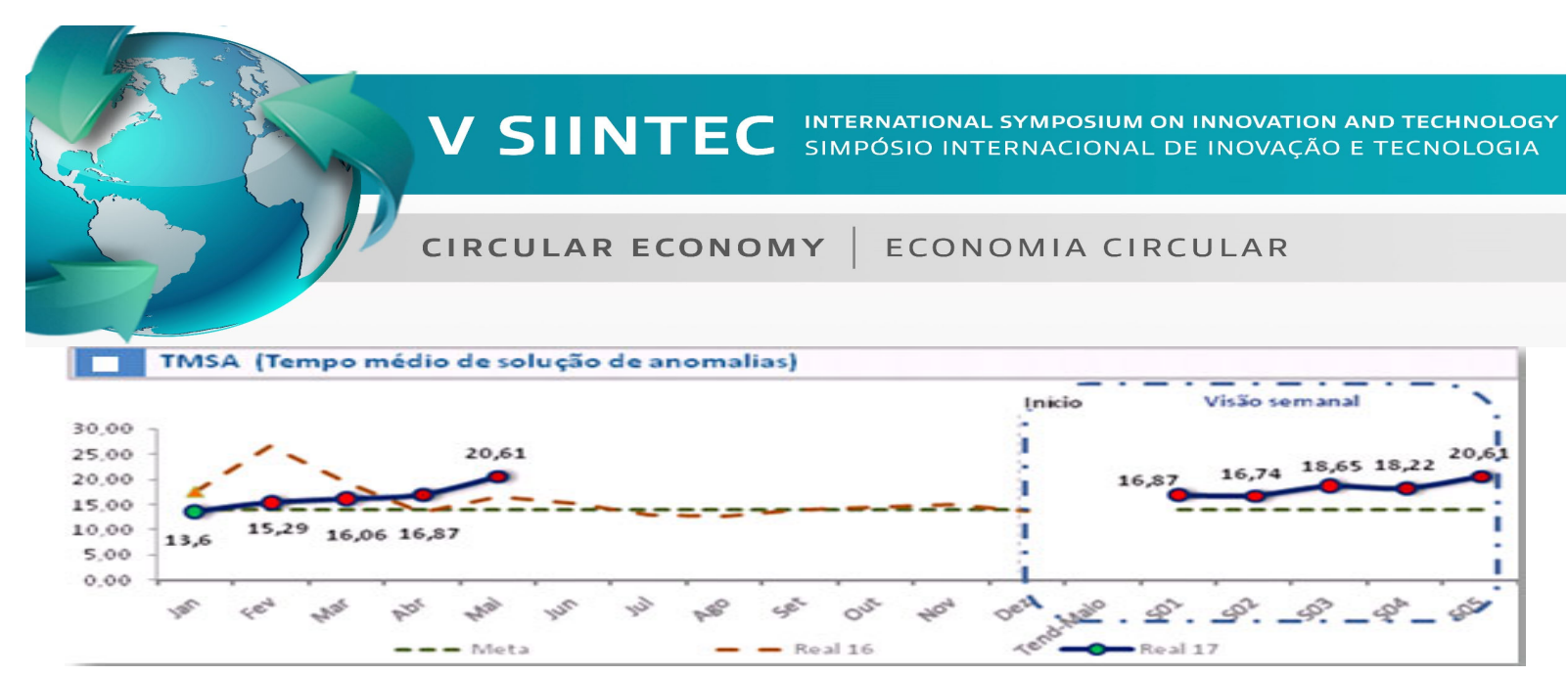

Gráfico 05: Tempo Médio de Solução de Anomalia

\section{CONCLUSÃO}

A implantação de um sistema móvel de gestão da manutenção, através do aplicativo SIGGA BRIZZO, proporcionou uma grande evolução na confiabilidade de manutenção, pois um dos motivos do baixo desempenho das linhas de produção foram os índices de manutenção decadentes. Os dados mostram que com o uso da ferramenta ficou mais fácil realizar as atividades programadas, com aumento do indicador de eficiência de programação, evolução no cumprimento da manutenção periódica, redução do backlog de ordens, redução no tempo médio de solução de anomalia, o que garante uma maior confiabilidade no processo produtivo, onde o cumprimento deste indicador significa manter os equipamentos em condições normais de funcionamento e consequentemente alta produtividade. Desta forma, através da aplicação do SIGGA BRIZZO na organização, pode-se afirmar que a manutenção passou a ter um maior controle das informações, contribuindo positivamente na gestão e nas tomadas de decisões, e trouxe ao setor de manutenção uma nova dinâmica na execução e detalhamento das suas informações gerando maior confiabilidade, disponibilidade, menor custo de manutenção, reduzindo retrabalho entre outros fatores.

\section{REFERÊNCIAS}

${ }^{1}$ RIBEIRO, C. R. Processo de implementação da Manutenção Produtiva Total (T.P.M) na indústria Brasileira. Taubaté, 2003.

2 DEMING, W. E. Dr. Deming: O Americano que Ensinou a Qualidade Total aos Japoneses. Rio de Janeiro: Record, 1993.

${ }^{3} \mathrm{HOLSBACH}$, Léria Rosane; VARANI, Márcio Luiz; CALIL, Saide Jorge.

Manutenção preventiva em equipamentos médico-hospitalares. Brasília; Anvisa; 2005.

${ }^{4}$ MARÇAL, R. F. M.; HATAKEYAMA, K CHIOCHETTA, J. C. Sistema de Gestão da Manutenção para a Pequena e Média Empresa . Florianópolis. 2004. 5 HEINRITZ, Stuart F.; FARRELL, Paul V. Compras: princípios e aplicações. São Paulo: Atlas, 1983.

${ }^{6}$ PINTO, Alan Kardec; XAVIER, Julio Aquino Nascif. Manutenção: Função

Estratégica. Rio de Janeiro: Qualitymark Ed., 2001.

${ }^{7}$ GIL, A. C. Métodos e técnicas de pesquisa. São Paulo: Atlas, 2002 